\title{
The influence of land use on nitrogen and sulfur turnover: a microbial approach
}

\author{
Yolanda Espín ${ }^{1, *}$, Guillermo Sanz ${ }^{1}$, Nicolás Valiente ${ }^{1}$, Alfonso Menchén $^{1}$, Beatriz Toledo ${ }^{1}$, \\ Manuel Álvarez-Ortí1 ${ }^{1}$ Susana Seseña ${ }^{2}$, and Juan José Gómez-Alday ${ }^{1}$ \\ ${ }^{1}$ Biotechnology and Natural Resources Section, Institute for Regional Development (IDR), University \\ of Castilla-La Mancha (UCLM), Campus Universitario s/n, 02071 Albacete, Spain \\ ${ }^{2}$ Department of Analytical Chemistry and Food Technology, Faculty of Environmental Sciences and \\ Biochemistry, UCLM, Avenida Carlos III s/n, 45071 Toledo, Spain
}

\begin{abstract}
Saline lakes are subject to numerous environmental impacts related to human activities. Pollution is one of the major threats to water bodies, since it produces the increase of nitrogen and sulfur contents, changing the chemical and biological conditions of the ecosystem. Microbially mediated redox processes exert a fundamental control on nutrient and contaminant turnover. Therefore, the aim of this study was to determine the influence of land use on the microbial communities responsible for $\mathrm{N}$ and $\mathrm{S}$ turnover in the lacustrine sediments from Pétrola Lake (SE Spain) disturbed by anthropogenic activities (agriculture, farming, mining, and wastewaters). To reach this goal, chemical and molecular tools (sequencing of 16S rDNA gene) were applied. The results showed the influence of land use on the chemistry and microbial community structure of the sediments from the saline lake. Compared to natural conditions, wastewater and mining showed the largest differences in terms of microbial structure as a result of salinity. These findings provide better understanding of how land use affects the water chemistry and the abundance of organisms responsible for nutrient turnover.
\end{abstract}

\section{Introduction}

Saline lakes are subject to numerous environmental impacts, closely related to human activities (e.g. agriculture, mining), which involve important ecological changes. Pollution of saline lakes occurs mainly through of agriculture return flows, wastewater and farming spill outs inputs. These threats, which increase the proportions of nitrogen and sulfur, produce important effects such as decreases in biodiversity which also affects to microbiota. Nitrogen $(\mathrm{N})$ is an essential nutrient for all organisms and its availability controls many aspects of ecosystem productivity. In aquatic ecosystems, nitrate $\left(\mathrm{NO}_{3}{ }^{-}\right)$is a widespread contaminant responsible for water degradation. It increases primary production in surface waters and, as a consequence, may lead to oxygen deficiency and further eutrophication of surface water bodies. Saline lakes have higher absolute rates of $\mathrm{N}$

\footnotetext{
* Corresponding author: Yolanda.Espin@alu.uclm.es
} 
removal processes than freshwater systems [1]. They therefore recycle nutrients more efficiently and have a high potential to remove compounds from agricultural runoff [2].

Another significant element is sulfur (S). Since sulfate $\left(\mathrm{SO}_{4}{ }^{2-}\right)$ is a common constituent of agricultural fertilizers, human practices in agricultural regions have increased the amount of $\mathrm{SO}_{4}{ }^{2-}$ in aquatic ecosystems and enhanced salinization of surface water and groundwater. Biogeochemical cycling involves the exchange of electrons between chemical species through reduction and oxidation (redox) reactions mediated by microorganisms. Microbially mediated redox processes exert a fundamental control on nutrient and contaminant turnover. Nitrogen and sulfur are key components in their most reduced form of biomolecules, including amino acids, nucleic acids and chlorophylls [3].

Previous studies have shown the influence of land use on the nitrogen removal pathways at basin scale (freshwater-saltwater interface) from Pétrola Lake [4], but little is known concerning to the water-sediment interface. The aim of this study was to determine the influence of land use on the microbial communities responsible for $\mathrm{N}$ and $\mathrm{S}$ turnover in the organic-rich sediments from Pétrola Lake (SE Spain). To reach this goal, chemical and molecular tools (sequencing of 16S rDNA gene) were applied.

\section{Material and methods}

\subsection{Study area}

Pétrola Lake is one of the most representative saline wetlands in the Castilla-La Mancha region and it is affected by noticeable anthropogenic pressures (irrigation, farming, urban wastewaters spills). The lake-aquifer system extends over $43 \mathrm{~km}^{2}$ and occupies the terminal discharge zone of an endorheic basin, where various small streams discharge into in a radial pattern. Agriculture involves approximately $75 \%$ of the total area, whereas the remaining area is occupied by semi-natural land cover types. Urban wastewaters from a population of 719 (year 2017) inhabitants are discharged directly into the lake without proper treatment. Moreover, mining activities had an important influence on the lake geomorphology until the nineties. Sampling points were distributed in 5 groups according to their proximity to the main anthropogenic pressures around the lake perimeter [4]. Sampling point 2651 is close to the depocenter of the Lake and corresponds with direct inputs of polluted water. Sites 2649 and 2652 are representative of areas where the discharge of synthetic and organic fertilizers from agriculture land uses (irrigation return flows) through nearby ephemeral streams takes place. Sites 2643 and 2650 are allocated where urban wastewaters from Pétrola village are discharged. Site 2648 is located close to the mouth of a man-made channel which discharges eluents from livestock directly to the lake. Site 2635 represents a separated pool for salt mining with limited communication with the lake.

\subsection{Sampling and chemical analysis}

A total of 49 water samples and 14 sediment samples were collected from 7 different sampling points (described above). The chemical parameters measured in water samples included $\mathrm{pH}$, redox potential (Eh), total dissolved solids (TDS), dissolved organic carbon (DOC), $\mathrm{SO}_{4}{ }^{2-}$, and ammonium $\left(\mathrm{NH}_{4}^{+}\right)$. A complete description of the methods used is included in [4].

In June $2017(n=7)$ and March $2018(n=7)$, organic-rich lacustrine sediments were collected from the described sampling sites. Sediment samples were collected from the bottom $5 \mathrm{~cm}$ using sterile polypropylene tubes, cooled, transported to the laboratory, and 
further used for DNA extraction and subsequent sequencing (cloning and sequence analysis).

\subsection{Sequencing}

The sampling preparation and analytical procedure was performed at the Institute for Regional Development (University of Castilla-La Mancha). In 2017, total genomic DNA was isolated from each sediment sample $(n=7)$ using the NucleoSpin ${ }^{\circledR}$ Soil kit from Macherey-Nagel according to the supplied protocol. 16S rDNA gene from each DNA extraction was amplified using primers 8F (5-AGAGTTTGATCCTGGCTCAG-3) and 1492R (5-TACCTTGTTAYGACTT-3). Cycling conditions were $95^{\circ} \mathrm{C}$ for $10 \mathrm{~min}$, followed by 35 cycles of $95^{\circ} \mathrm{C}$ for $1 \mathrm{~min}, 53^{\circ} \mathrm{C}$ for $1 \mathrm{~min}$ and $72^{\circ} \mathrm{C}$ for $1 \mathrm{~min}$, with a final step of $72^{\circ} \mathrm{C}$ for $7 \mathrm{~min}$. PCR product was cloned using the pGEM ${ }^{\circledR}-\mathrm{T}$ Easy Vector System (Promega). Transformed cells were plated in LB/Ampicillin/IPTG/X-Gal plates. 24 to 30 colonies from each plate were selected to perform the sequence analysis, were picked and incubated in LB liquid medium with ampicillin overnight at $37^{\circ} \mathrm{C}$. After plasmidic extraction, clones $(n=180)$ were sequenced and each $16 \mathrm{~S}$ rDNA was compared with BLASTn library from NCBI. In 2018, total genomic DNA from sediment samples $(n=7)$ was isolated with the same kit for metagenomic analysis. The abundance of the bacterial communities has been correlated to the chemical measured values by means of factor analysis based on principal component analysis (PCA). Results of statistical tests were considered to be significant at the confidence level 95\% $(p<0.05)$.

\section{Results and discussion}

\subsection{Hydrochemical data}

Mean values of the chemical parameters measured are included in Table 1. $\mathrm{pH}$ values were similar in all the studied zones. Concerning redox potential (Eh), values found in the 5 zones were favourable to promote microbially mediated redox processes. Mining zone showed the highest values of salinity (TDS), $\mathrm{SO}_{4}{ }^{2-}$ and DOC. The increase in salinity can be explained by the fact that mining pool, because of its isolation, is affected to a greater extent by the effects of evapoconcentration. On the other hand, the high concentrations of DOC measured may be produced by both evapoconcentration processes and the high primary productivity found at the pool. The lowest values of $\mathrm{SO}_{4}{ }^{2-}$ were found in wastewaters zone, which can be explained by the dilution produced by the freshwater polluted inputs from urban wastes. Concerning $\mathrm{NH}_{4}{ }^{+}$, the highest value was found in the Farming zone, as a result of the inputs from livestock wastes spilled into the lake.

Table 1. Mean hydrochemical values in water and sediment samples between 2017 and 2018.

\begin{tabular}{|l|c|c|c|c|c|}
\cline { 2 - 6 } \multicolumn{1}{c|}{} & Lake & Agriculture & Farming & Mining & Wastewater \\
\hline $\mathrm{pH}$ & $8.7 \pm 0.3$ & $8.7 \pm 0.4$ & $8.6 \pm 0.3$ & $8.4 \pm 0.4$ & $8.6 \pm 0.4$ \\
\hline $\mathrm{Eh}(\mathrm{mV})$ & $-79 \pm 170$ & $-23 \pm 175$ & $-51 \pm 139$ & $32 \pm 137$ & $-11 \pm 178$ \\
\hline $\mathrm{TDS}(\mathrm{g} / \mathrm{L})$ & $43.7 \pm 6.2$ & $40.7 \pm 9.1$ & $42.3 \pm 7.2$ & $48.4 \pm 4.7$ & $29.8 \pm 19.2$ \\
\hline $\mathrm{DOC}(\mathrm{mg} / \mathrm{L})$ & $93.4 \pm 43.2$ & $94.3 \pm 38.8$ & $105.7 \pm 2.7$ & $317.5 \pm 54.4$ & $93.4 \pm 55.7$ \\
\hline $\mathrm{SO}_{4}{ }^{2-}(\mathrm{g} / \mathrm{L})$ & $26.8 \pm 1.4$ & $26.8 \pm 1.0$ & $22.3 \pm 1.7$ & $44.0 \pm 0.8$ & $13.9 \pm 14.2$ \\
\hline $\mathrm{NH}_{4}{ }^{+}(\mathrm{mg} / \mathrm{L})$ & $0.23 \pm 0.26$ & $0.15 \pm 0.17$ & $0.37 \pm 0.32$ & $0.12 \pm 0.16$ & $0.06 \pm 0.07$ \\
\hline
\end{tabular}




\subsection{Diversity of the microbial community}

Results obtained from sequence analysis are summarized in Figure 1, where the relative abundance of families per land-use zone is shown. Large differences between zones and sampling campaigns are revealed. Sequences from Lake zone can be considered as control conditions, since these are not influenced by direct inputs from anthropogenic activities. In Lake zone, Rhodobacteraceae, which are deeply involved in S-N biogeochemical cycling, and Trueperaceae, which include chemo-organotrophic and aerobic species oxidants of fatty acids, were the most abundant families. Wastewaters zone showed the highest diversity: the most abundant phyla were Desulfobacteraceae, which are typical sulfate and sulphite reducers, Anaerolineaceae, which are methanogens and also are associated with reductive processes of $\mathrm{N}$ and $\mathrm{S}$, and Trueperaceae. In this zone, reducing conditions are present (Table 1). Mining zone showed a greater abundance of Desulfobacteraceae, Spirochaetaceae (responsible for many human diseases and elemental sulfur reduction) and Halomonadaceae (halophilic organisms able to perform nitrate reduction). Mining zone showed the highest salinity values, which is reflected in the microbial diversity. Sequencing from Farming zone in 2018 showed a similar pattern than those described above. However, phyla abundance in 2017 showed a greater abundance of Rhodobacteraceae, and Ectothiorhodospiraceae, which involve purple $\mathrm{S}$ bacteria and some $\mathrm{NO}_{3}{ }^{-}$reducers. Agriculture zones showed the greatest influence derived from families Rhodobacteraeceae, Desulfobacteraceae, and Anaerolineaceae.

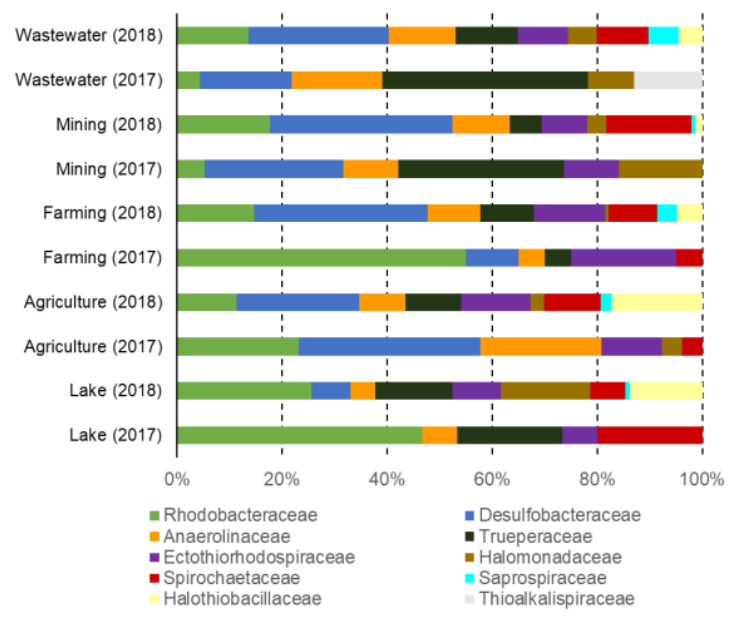

Fig. 1. Relative abundance of the dominant bacterial groups studied $(n=10)$ observed in sediment samples during 2017 (cloning and sequencing) and 2018 (metagenomic analysis).

\subsection{Environmental connections between chemical and biological parameters}

PCA loadings based on chemical and microbial diversity are given in Figure 2. The two principal components (PC) considered accounted for $54.1 \%$ of the total variance. PCA clearly separated chemical parameters in two groups. PC1 was composed of chemical parameters in water samples. There, salinity (TDS), $\mathrm{SO}_{4}{ }^{2-}, \mathrm{DOC}$, and redox potential (Eh) parameters were separated towards the right side of the biplot. On the contrary, $\mathrm{pH}$ and $\mathrm{NH}_{4}{ }^{+}$were aligned to the left side of the plot. Concerning PC2, it included the microbial diversity. Families were separated from the bottom of the biplot (Thioalkalispiraceae and Anaerolineaceae, anaerobic species) towards the top of the biplot, where Rhodobacteraceae (with either strictly aerobic or facultatively anaerobic respiratory 
metabolism), Ectothiorhodospiraceae (which included aerobic species), and Spirochaetaceae (which also included some aerobic species). Therefore, the separation among families responded to oxic/anoxic conditions. Moreover, families like Rhodobacteraceae and Ectothiorhodospiraceae, which include species able to perform $\mathrm{NO}_{3}{ }^{-}$reduction, were aligned close to $\mathrm{NH}_{4}{ }^{+}$suggesting a connection with $\mathrm{N}$ cycle. While nutrient accumulation often has little effect on microbial community structure [5], a "bacterial" gradient is observed according to salinity and organic carbon content, from Thioalkalispiraceae (salt-tolerant species) to Halomonadaceae (halophilic bacteria). These results suggest that the increase in salinity can modify the microbial community structure.

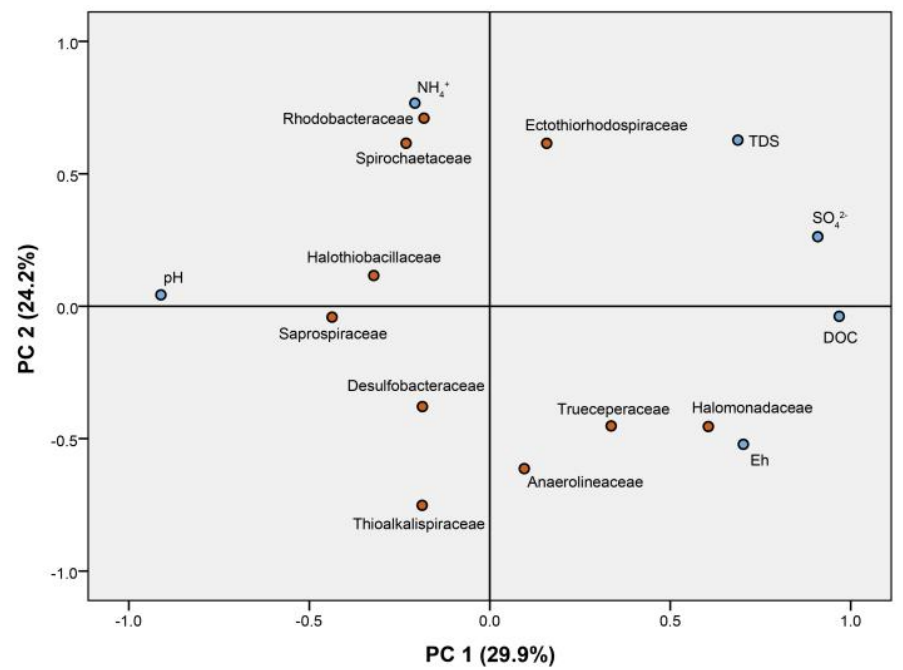

Fig. 2. Principal component analysis of samples based on chemical and microbiological characterization of sediment samples.

\section{Conclusions}

This study has shown the influence of land use on the microbial community structure of the sediments from a saline lake. Compared to natural (lake) conditions, wastewater and mining showed the largest differences in terms of microbial structure as a result of lower and higher salinity levels, respectively. In terms of microbial diversity, differences between natural conditions, farming and agriculture cannot be explained only using chemical parameters considered. These findings provide better understanding of how land use affects the water chemistry and the abundance of organisms responsible for nutrient turnover. However, further research is required including more parameters (e.g. stable isotopes).

This work was funded by the projects SBPLY/17/180501/000296 from the Castilla-La Mancha Government, and CGL2017-87216-C4-2-R from the Spanish Government.

\section{References}

1. S. Blomqvist, A. Gunnars, R. Elmgren, Limnol. Oceanogr. 49, 2236-2241 (2004)

2. M.M. Brinson, R.D. Rheinhardt, F.R. Hauer, L.C. Lee, W.L. Nutter, R.D. Smith, D. Whigham, A guidebook for application of hydrogeomorphic assessments to riverine wetlands. Wetlands Research Program Technical Report (1995) 
3. A.J.B. Zehnder, S.H. Zinder, The natural environment and the biogeochemical cycles (1980)

4. N. Valiente, R. Carrey, N. Otero, A. Soler, D. Sanz, A. Muñoz-Martín, F. Jirsa, W. Wanek, J.J. Gómez-Alday, Sci. Total Environ. 631, 649-659 (2018)

5. L.A. Ogilvie, P.R. Hirsch, A.W. Johnston, Microb. Ecol. 56, 525-537 (2008) 